\title{
Determining the angle of femoral torsion and association with shaft length and mid circumference
}

\author{
Subodh Kumar Yadav ${ }^{1}$, Sanjenbam Arun Chandra Singh², Renu Yadav ${ }^{3}$ \\ ${ }^{1}$ Assistant Professor, ${ }^{2}$ Professor, Department of Anatomy, ${ }^{3}$ Assistant Professor, Department of Physiology, Nobel \\ Medical College, Biratnagar, Nepal
}

Background: Angle of femoral torsion has an anatomical variation based on sex, geography, ethnicity and occupation and concludes various impact factor on determining the angulation as well as the length of the bone. Aims and Objective: Thus, present study is aimed to determine the angle of femoral torsion in Nepalese population. Materials and Methods: This is a cross-sectional study carried out at the Department of Anatomy, Nobel Medical College and Teaching Hospital, Biratnagar, Nepal. Of the total 60, unpaired and unknown gender, dry femora were collected during one year period and separated as right sided $(n=30)$ and left sided $(n=30)$ according to the standard anatomical landmarks. Measurement of angle was done by Kingsley Olmsted method and the length, mid-circumference by measuring tape. Results: The angle of torsion in dry femora $(n=60)$ for right $(16.73 \pm 3.095)$ and left $(16.67 \pm 2.963)$ side were recorded. The mean shaft length, mid circumference for right sided femora were recorded as $39.367 \pm 0.9185$ and $7.933 \pm 0.6661 \mathrm{~cm}$ respectively. The mean shaft length and mid circumference were $38.917 \pm 0.8914$ and $7.933 \pm$ $0.5833 \mathrm{~cm}$ respectively for left sided femora. Differences $(A T F, p=0.932, L F, P=0.059$, $\mathrm{MCF}, \mathrm{P}=1$ ) of variables between right and left femora were analyzed and correlation of angle of femoral torsion with shaft length and midshaft circumference (ATF vs MCF, $p=0.571$ and LF, $p=0.153$ ) was done. Conclusion: Documenting the femoral angle of torsion with shaft length, midshaft circumference in normal dry femora of cadaver is of great importance for Orthopedic surgeons since it provides a knowledge for planning the hip surgeries.

Key words: Femoral angle; Bicondylar plane; Midshaft circumference; Kingsley Olmsted; Cadaver
Access this article online

Website:

http://nepjol.info/index.php/AJMS

DOI: $10.3126 /$ ajms.v11i3.27121

E-ISSN: 2091-0576

P-ISSN: $2467-9100$

Copyright (c) 2020 Asian Journal of Medical Sciences

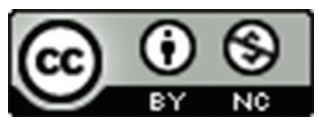

This work is licensed under a Creative Commons Attribution-NonCommercial 4.0 International License.

\section{INTRODUCTION}

The angle of femoral torsion (AFT) can be defined as angle formed by femoral condyle's plane (bicondylar plane) and a plane passing through the center of the neck and femoral head. If the axis of the neck inclines forward to transcondylar plane the AFT is called femoral neck anteversion (FNA), if it points posterior to transcondylar plane it is called femoral neck retroversion. If it is in the same line as of transcondylar plane it is known as neutral version. ${ }^{1}$ The angulation and torsion of the proximal femur in normal populations become a concern for the orthopedic surgeon for surgical background and thus has been subject to research for decades. ${ }^{2}$

Understanding and treatment of pathologic conditions in the hip joint must be supported by exact knowledge of the normal values of these parameters, especially in growing children, but also in skeletally mature patients. ${ }^{3} \mathrm{~A}$ study has determined the value of AFT at birth to be 40 degrees and with advancing age it decreases gradually to 20 degrees at ten to around 8 to 15 degrees in adulthood..$^{4-6} \mathrm{~A}$ comparative study between median torsion angle in Caucasians and Asians was recorded not more than $15^{\circ}\left(5.5-21.4^{\circ}\right) .^{7}$ Again 
the another study documented the anteversion angle ranged from $12.10^{\circ}$ to $17.59^{\circ}$ to the right and from $14.77^{\circ}$ to $19.73^{\circ}$ to the left, making an average of $14.84^{\circ} \pm 7.60^{\circ}$ in right and $17.25^{\circ} \pm 6.89^{\circ}$ in left. ${ }^{8}$ Koerner et al. found markedly higher $(8 \%)$ proportions of retroverted hips in their study population, ranging from $23.5 \%$ in African American females to $7.2 \%$ in Hispanic males. This difference is probably methodological: In Koerner's study, a 2D-CT model was used. ${ }^{9}$ There are variations among studies. Excessive femoral torsion may be associated with certain neurologic and orthopedic concern. Some of the reported conditions like children with cerebral palsy having excessive angle of femoral torsion. Thus, the clear understanding of femoral torsion has become essential for the treatment of pathologic conditions of hip joint, skeletally mature patients and also for growing children. ${ }^{10}$ Thus, not only the FNA but also the AFT do have an association with many clinical problems regarding the surgical treatment in femur, which could be a reason for parents concern for children future, and prosthesis, hip and knee replacement in adults. Thus, present study is basically concern on determining the angle of femoral torsion in cadaver's dry femur by standard measurement process and finding the correlation of shaft length, mid-circumference with angle of femoral torsion.

\section{MATERIALS AND METHODS}

This is a cross-sectional study carried out at the Department of Anatomy, Nobel Medical College \& Teaching Hospital, Biratnagar, Nepal from April 2017 to December 2017. Femur bone of Nepalese origin of either sex and age available at the department of Anatomy of Nobel Medical College were used for the study.

The total of 60 unpaired dry femora without any gross abnormality were included which were well preserved. All 60 femora of unknown gender were, first separated as right sided $(\mathrm{n}=30)$ and left sided $(\mathrm{n}=30)$ according to the standard anatomical landmarks observed. Damaged and deformed bones were excluded from the study. The length and mid shaft circumference of each bone was measured with the help of measuring tape.

Angle of torsion was measured by Kingsley Olmsted method $^{11}$ by placing specimen at the edge of a plane horizontal table so that femoral condyles rest on the flat surface. Then horizontal limb of a goniometer was fixed at the edge of the experimental table. The vertical limb was held parallel along the axis of head and neck of the femur. The vertical limb was passing through the center of head of femur extending from a point where transverse diameter is maximum to the center point on greater tuberosity of femur. The horizontal limb axis was taken as line passing between the centers of two epicondyles of femur. The angle subtended between the horizontal axis (transcondylar plane) with the axis of head and neck of the femur was measured and recorded from the goniometer. To improve the observer's reliability the whole procedure was repeated by different investigator for the same collected samples.

\section{Data analysis}

Descriptive Analysis of different variables was done. The means and standard deviation (SD) with 95\% confidence intervals (CI) of the angle of femoral torsion for all the femursas well as the length and mi-circumference for each were recorded. The independent sample t-test was used to check for significant differences $(p<0.05)$ between the right and left femora were analyzed. Also, the Pearson Correlation of angle of femoral torsion with length and mid-circumference were analyzed. SPSS software version 25 was used for statistical analysis of variables.

\section{RESULTS}

The total of 60 unpaired dry femora without any gross abnormality of either sex which were well preserved were included in the study. After segregating as right or left side according to standard anatomical criteria the subtended angle was recorded.

The Table 1 showed the average (mean \pm SD) angle of torsion in $60 \mathrm{dry}$ femora were observed $16.73 \pm 3.095^{\circ}$ for right side and $16.67 \pm 2.963^{\circ}$ for left side. The mean length and mid-circumference of right sided femora were observed as $39.367 \pm 0.9185^{\circ}$ and $7.933 \pm 0.6661^{\circ}$ respectively. The mean length and mid-circumference of left sided femora were observed as $38.917 \pm 0.8914^{\circ}$ and $7.933 \pm 0.5833^{\circ}$ respectively.

Table 2 shows statistical analysis by unpaired " $\mathrm{t}$ " test (Levene's Test) assuming the equal variance, there was no

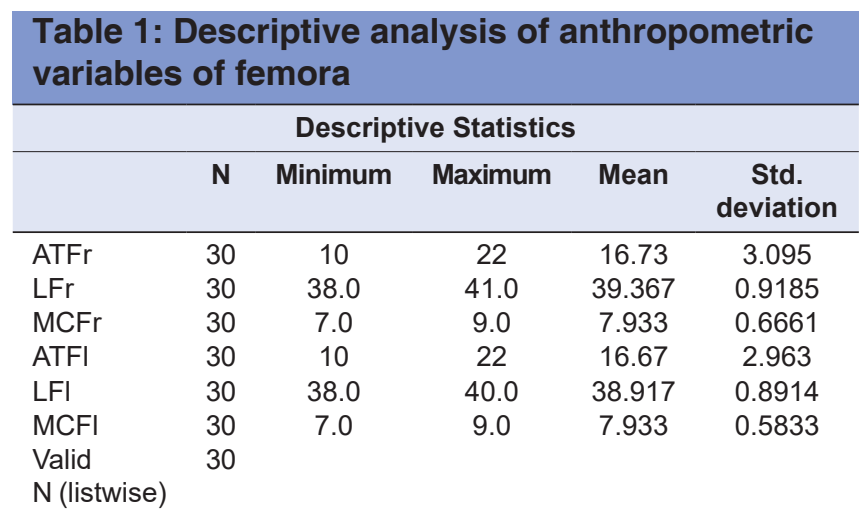

ATFr=Right side femoral angle of torsion, LFr=Length of femur of right side, $\mathrm{MCFr}=$ Midshaft circumference of right side, ATFI=Left side femoral angle of torsion, LFI=Length of femur of left side, MCFI=Midshaft circumference of left side 
significant difference between right and left femoral torsion angle, length and mid circumference.

The correlation between angle of torsion and mid-shaft circumferencewas inversely proportional though it was statistically non-significant. Similarly, the angle of torsion and the length of the femur was estimated to be directly proportional but statistically non-significant (Table 3).

\section{DISCUSSION}

The present study is an attempt to evaluate the normal angle of torsion with dry femora collected from the Anatomy laboratory of Nobel Medical College for documenting the normal range of angle of femoral torsion from cadavers. This study would be useful in orthopedic surgery for various hip pathologies.

The normal data obtained from the present study showed that the minimum value of angle of torsion was $10 \mathrm{~cm}$ and the maximum was found to be $22 \mathrm{~cm}$ for both right and left. The mean value recorded from the study was $16.73 \pm 3.095^{\circ}$ for right side and $16.67 \pm 2.963^{\circ}$ for left side. A study done among population of Maharashtra in unpaired 280 dry adult femora by Dwivedi and Bhatnagar ${ }^{12}$ also estimated average anteversion in males to be $11.23^{\circ}$ and $13.39^{\circ}$ on left and right sides, respectively and in female femora $13.23^{\circ}$ and $16.21^{\circ}$ on the left and right sides, respectively. According to Deswal et al ${ }^{13}$ measurement of angles of femur bone was observed to be $19.75 \pm 7.75^{\circ}$ on right side and $15.75 \pm 7.13^{\circ}$ on left sides. The result of present study concurs with the findings of the study by Dwivedi and Bhatnagar.

The median torsion angle for Caucasians was $14.2^{\circ}$ (IQR 8.1-20.3 ${ }^{\circ}$; the median torsion angle for Asian was

\begin{tabular}{lcccc}
\multicolumn{3}{l}{ Table 2: Independent sample “ $\boldsymbol{t}$ " test assuming } \\
equal variance for right and left femora
\end{tabular}

ATF=Femoral angle of torsion, LF=Length of femur, MCF=Midshaft circumference

\begin{tabular}{|c|c|c|c|}
\hline Variables & Variables & $\begin{array}{c}\text { Pearson } \\
\text { correlation }(r)\end{array}$ & $P$ value \\
\hline ATF & $\begin{array}{l}\text { MCF } \\
\text { LF }\end{array}$ & $\begin{array}{r}-0.075 \\
0.153\end{array}$ & $\begin{array}{l}0.571 \\
0.244\end{array}$ \\
\hline
\end{tabular}

$14.7^{\circ}\left(5.5-21.4^{\circ}\right)$ in a study by Maximilian J. Hartel in Germany. ${ }^{7}$ The observed value of Asian were found to be similar with our recorded mean value which is $16.73^{\circ}$ for right sided and $16.67^{\circ}$ for left sided femora.

One of the studies in BPKIHS, Dharan Nepal, the estimated mean length of femoral boneand mid shaft circumference were calculated to be $41.93 \pm 2.47 \mathrm{~cm}$, $8.31 \pm 0.59 \mathrm{~cm}$ respectively. ${ }^{14}$ Femur length recorded in our study were; right side $=39.367 \pm 0.9185 \mathrm{~cm}$, left side $=38.917 \pm 0.8914 \mathrm{~cm}$ and measurement of midcircumference for right side $=7.933 \pm 0.6661 \mathrm{~cm}$, left side $=7.933 \pm 0.5833 \mathrm{~cm}$.

The results of the study in Tamil Nadu, India by S Dhivya, $\mathrm{V}$ Nandhini, ${ }^{15}$ the mean length of femur was $41.66 \mathrm{~cm}$ (left femur was $41.88 \mathrm{~cm}$ and right femur was $41.29 \mathrm{~cm}$ ). The result of present study where right-sided shaft length was observed as $39.120 \pm 0.9560 \mathrm{cmand}$ left sided shaft length as $38.890 \pm 0.8765 \mathrm{~cm}$ which seems to be comparable with the above study.

\section{CONCLUSION}

Documenting the femoral angle of torsion in normal dry femora of cadaver has been considered to be of great importance for Orthopedic surgeons in particular. Knowledge of not only the angle of torsion but also the shaft length as well as the mid-shaft circumference is quite applicable in planning for hip replacement and other prosthetic surgeries. The study concludes that the anatomy of the femur structure among the Asians are quite similar in measurement. Thus, the present study provides the valuable information for orthopedic surgeons.

\section{ACKNOWLEDGEMENT}

We would like to acknowledge Mr. Santosh Kumar Raut, technician from department of Anatomy for his great assistance throughout the research especially during the data collection.

\section{REFERENCES}

1. Zalawadia A, Ruparelia S, Shah S, Parekh D, Patel S, Rathod SP, et al. Study of femoral neck anteversion of adult dry femora in Gujarat region. NJIRM. 2010;1:1-5.

2. Buck FM, Guggenberger R, Koch PP and Pfirmann CWA. Femoral and Tibial Torsion Measurements With 3D Models Based on Low-Dose Biplanar Radiographs in Comparison with Standard CT Measurements. Am J Roentgenol 2012; 199: 607-612.

https://doi.org/10.2214/AJR.11.8295

3. Ejnisman L, Philippon MJ, Lertwanich P, Pennock AT, Herzog 
MM, Briggs KK, etal. Relationship Between Femoral Anteversion and Findings in Hips with Femoroacetabular Impingement. Orthopedics 2013;36:293-300.

https://doi.org/10.3928/01477447-20130222-17

4. Schoenecker PL, Rich MM. The lower extremity. In In: Morrissey RT, Weinstein SL, editors. Lovell and Winter's Pediatric Orthopaedics. 6. Lippincott Williams and Wilkins; Philadelphia: 2006:1157-211.

5. Harkess J. Arthroplasty of hip In. In: Canale ST, Mosby, editors. In Campbell's Operative Orthopaedics.10. Philadelphia: 2003: 315-482.

6. Hefti F, Brunner R, Hasler CC and Jundt G. Pediatric Orthopedics in Practice. Springer; Verlag Berlin Heidelberg: 2007:169-170.

7. Hartel MJ, Petersik A, Schmidt A, Kendoff D, Nüchtern J, Rueger JM, et al. Determination of Femoral Neck Angle and Torsion Angle Utilizing a Novel Three-Dimensional Modeling and Analytical Technology Based on CT Datasets. PLOS ONE 2016 11(3): e0149480.

https://doi.org/10.1371/journal.pone.0149480

8. De Tavares Canto RS, Anjos Filho GS, Magalhães L, Moreira MQ, de Tavares Canto FR, Antonio Baraúna M, et al. Femoral neck ante version: a clinical verses radiological evaluation. Acta ortop bras 2005; 13 (4): 171-174.

https://doi.org/10.1590/S1413-78522005000400003

9. Koerner JD, Patel NM, Yoon RS, Sirkin MS, Reilly MC and Liporace FA. Femoral version of the general population: does "normal" vary by gender or ethnicity? J OrthopTrauma2013; 27:308-311.

https://doi.org/10.1097/BOT.0b013e3182693fdd

10. Jouvea JL, Glarda Y, Garrona E, Piercecchia MD, Dutour O and Tardieu C. Anatomical study of the proximal femur in the fetus. J Pediatr Orthop B 2005;14(2):105-110. https://doi.org/10.1097/01202412-200503000-00009

11. Kingsley PC and Olmsted KL. A study to determine the angle of anteversion of the neck of the femur. J Bone Joint Surg Am 1948; 30A:745-751. https://doi.org/10.2106/00004623-194830030-00021

12. Dwivedi AK and Bhatnagar R. Anthropometric study of angle of femoral torsion in Maharashtrian population. Med J DY Patil Univ 2016; 9:200-203. https://doi.org/10.4103/0975-2870.177664

13. Deswal A, Saxena AK and Bala A. Measurement of Angles of Femur Bone. International Journal of Scientific Study 2017; 5(1): 97-99.

14. Khanal L, Shah $S$ and Koirala S. Method of estimation of total length of femur bone from its longitudinal segmental measurements and mid-shaft circumference in Nepalese population. Eur J Forensic Sci 2017; 4(3): 1-5. https://doi.org/10.5455/ejfs.253517

15. Dhivya $S$ and Nandhini V. A Study of Certain Femoral Metrics in South Indian Population and its Clinical Importance. Int J Sci Stud 2015; 3(7):132-135.

\section{Authors Contribution:}

SKY-Concept and design of the study, manuscript preparation, statistically analyzed and interpreted, critical revision of the manuscript; SACS- Critical revision of manuscript and review of the study; RY- reviewed the literature, collected data.

Work attributed to:

Department of Anatomy, Nobel Medical College and Teaching Hospital, Biratnagar, Nepal.

Orcid ID:

Dr. Subodh Kumar Yadav - (i) https://orcid.org/0000-0002-8482-5928

Dr. Sanjenbam Arun Chandra Singh - (1) https://orcid.org/0000-0001-6764-6269

Dr. Renu Yadav - (D) http://orcid.org/0000-0002-8126-6585

Source of Support: None, Conflicts of Interest: None. 